\title{
Lower Tinetti scores can support an early diagnosis of spatial neglect in post-stroke patients
}

\author{
Paola COLOMBO 1, Giovanni TAVEGGIA ${ }^{1}$, Deborah CHIESA 1 *, \\ Rachele PENATI ${ }^{2}$, Monica TIBONI ${ }^{3}$, Liala DE ARMAS ${ }^{1}$, Roberto CASALE 4
}

${ }^{1}$ Unit of Rehabilitation, Faccanoni Hospital, Habilita Care\&Research Hospitals, Sarnico, Bergamo, Italy; ${ }^{2}$ Department of ClinicalSurgical, Diagnostic and Pediatric Sciences, University of Pavia, Pavia, Italy; ${ }^{3}$ Department of Mechanical and Industrial Engineering, University of Brescia, Brescia, Italy; ${ }^{4}$ Istituto di Neuroriabilitazione ad Alta Complessità, Habilita Care\&Research Hospitals, Zingonia di Ciserano, Bergamo, Italy

*Corresponding author: Deborah Chiesa, Unit of Rehabilitation, Faccanoni Hospital, Habilita Care\&Research Hospitals, Via P. A. Faccanoni 6, 24067 Sarnico, Bergamo, Italy. E-mail: chiesa.deborah@gmail.com

\section{A B S T R A C T}

BACKGROUND: Neglect represents a severe complication of stroke, which impairs patients' daily activities. An early diagnosis of neglect is fundamental for management decisions.

AIM: The aim of this study is to evaluate the usefulness of the Tinetti Test as an outcome of spatial neglect in post-stroke patients.

DESIGN: Observational retrospective data analysis.

SETTING: Rehabilitation Hospital.

POPULATION: Cohort of post-stroke adults admitted in our Rehabilitation Unit.

METHODS: One hundred and sixty stroke patients were evaluated between the $1^{\text {st }}$ of January 2015 and the $31^{\text {st }}$ of December 2016 at our Department. Eighty-nine inpatients matched the inclusion criteria. Their scores of the Tinetti Test for balance condition and gait function were compared with Bells Test and line bisection task for spatial neglect. Global independence activity was also assessed using Barthel Index and global cognitive functioning by means of the Mini-Mental State Examination.

RESULTS: Twenty-two patients between the 89 patients included in this study were affected by spatial neglect at admission. A high statistical significant correlation was observed between lower Tinetti scores and neglect presence (mean Tinetti Score: 2.36 neglect; 7.82 non-neglect; $\mathrm{P}<0.001$ )

CONCLUSIONS: The Tinetti Test is a well-established assessment scale to measure balance ability and gait function in post-stroke patients. Results from this study suggest that Tinetti Test may be considered as an early ecological screening tool for the diagnosis of neglect in poststroke patients.

CLINICAL REHABILITATION IMPACT: The alternative use of the Tinetti Test for the diagnosis of spatial neglect.

(Cite this article as: Colombo P, Taveggia G, Chiesa D, Penati R Tiboni M, De Armas L, et al. Lower Tinetti scores can support an early diagnosis of spatial neglect in post-stroke patients. Eur J Phys Rehabil Med 2019;55:722-7. DOI: 10.23736/S1973-9087.19.05448-0)

KEY WORDS: Perceptual disorders; Stroke; Early diagnosis.

Sity troke is one of the main causes of disability; the majority of stroke patients have a combination of sensory, motor, cognitive and emotional impairment, which often lead to severe restrictions in their abilities to perform basic activities of daily living (ADL). ${ }^{1}$ Individuals with stroke experience a severe loss of postural control, which results in a high incidence of falls both during and after rehabilitation, mainly in patients affected by sensorimotor and cognitive deficits, such as spatial neglect. ${ }^{2,3}$ Indeed the pres- ence of a spatial neglect is usually associated with poor functional outcomes and higher requirements for assisted care and an increased risk of falling. ${ }^{4,5}$

The Tinetti Test ${ }^{6}$ is commonly used to assess risk of falls in patients with neurological diseases. It has been shown to be useful to evaluate vestibular conditions and gait function in people after stroke; it does not require sophisticated equipment to be applied and it is trusted to detect significant changes during neuro-rehabilitation treatment. ${ }^{7-9}$ 


\section{COPYRIGHT $^{\circledR} 2019$ EDIZIONI MINERVA MEDICA}

Different studies in patients with severe stroke, following the acute event, have extensively shown a negative influence of neglect on postural stability and body positioning characterized by a lesional tilt, away to the central body line. ${ }^{10-12}$ Some studies have indicated more severe loading asymmetry and postural instability in patients with right compared to left hemisphere lesions, most probably related to the presence of visuo-spatial neglect. ${ }^{13}$ For what concerns voluntary lateral weight-shifting capacity, postacute patients with neglect performed $10-20 \%$ slower than those without neglect, which was related with a relatively long weight-transfer time towards the paretic leg. ${ }^{14}$ It is important to use reliable tools to measure the quality of patient's life, the effectiveness of therapy and the social costs..$^{15}$ Two studies ${ }^{16,17}$ about tools for measuring neglect demonstrated that participants with neglect missed significantly more left-sided targets than controls and that this neglect is also associated with the performance in common neglect tasks. During the carrying out of complex actions, the functional limits of the patient emerge consistently. It has been shown how multitask demands lead to neglect worsening. ${ }^{18}$ Bowen et al. have highlighted the weakness of many clinical neglect trials due to the lack of ecologically valid test that properly evaluate the usefulness of treatments to improve ordinary skills in persons with neglect. 19

The aim of this study was to evaluate the possibility to predict diagnosis of neglect in post-stroke patients using the Tinetti Index, a task on demands toll that could prove efficient at detecting neglect in ecological skills. ${ }^{20}$

\section{Materials and methods}

\section{Participants}

Post-stroke patients were assessed for eligibility and selected patients were hospitalized in our neuro-rehabilitation Institute between $1^{\text {st }}$ January 2015 and $31^{\text {st }}$ December 2016.

Inclusion criteria for the current study were: 1) clinical and radiological diagnosis of stroke (ischemic or hemorrhagic, confirmed with CT or MRI scans); 2) presence of an unilateral hemisphere lesion; 3 ) age $\geq 18$ years; d) MMSE $\geq 15$ at initial assessment (performed by the neuropsychologist) and e) stable clinical conditions. Exclusion criteria for this study were: 1) previous vestibular disorders; 2) presence of bilateral lesions; and 3) presence of severe aphasia or severe cognitive impairment

The study waived ethical approval because it was a retrospective data analysis, relying on measurements and data acquisition, which are performed as part of the daily routine care. Any informed consent from human subjects was obtained as required.

\section{Procedure and tasks}

We reviewed the patient's medical record and collected demographic and clinical characteristics. All patients were assessed with the Tinetti Balance and Gait Test to detect balance condition and gait function, which was performed within the first two weeks after admission to our rehabilitation center. Global independence in activity was assessed using the Barthel Index (BI), ${ }^{21}$ which measures the extent to which stroke patients can function independently in their activities of daily living (ADL). Spatial neglect was subsequently assessed with paper and pencil tasks (the Bells Test and a line bisection task). Global cognitive functioning was screened with the Mini-Mental State Examination (MMSE).22, 23

Even BI, the Bells Test and a line bisection task and MMSE were performed within the first two weeks after admission, as for the Tinetti Test.

\section{Tinetti Test}

The Tinetti Test is a standardized evaluation of stability and mobility. ${ }^{6}$ Balance and gait are assessed and scored individually in a 16-item test. Balance, which is assessed first, is judged while sitting, arising, standing (immediate and prolonged), and turning. Additionally, maintenance of balance is tested against attempts at disruption (nudge) and without a horizon reference (eyes closed). These indicate body control and strength. In gait testing, right and left feet are evaluated separately for swing (step length) and clearance and then compared for step symmetry and continuity. Additionally, path deviation, trunk stability and stance (normal or wide-based) are evaluated during walking. The scores range from 0 to 28 , where 0 is attributed to patients forced to bed and 28 is the score of a normal balance and gait.

\section{Global independence}

BI is an ordinal scale used to measure performance in ADL..$^{21}$ For many years, it has been the mainstay of measuring functional abilities in rehabilitation patients. It has been used both in the management of patients and in the evaluation of the efficacy of rehabilitation programs.

The items can be divided into a group that is related to self-care (feeding, grooming, bathing, dressing, bowel and 


\section{COPYRIGHT $^{\odot} 2019$ EDIZIONI MINERVA MEDICA}

bladder care, and toilet use) and a group related to mobility (ambulation, transfers, and stair climbing). The score ranges from zero, representing a totally dependent bedridden state, to one hundred, which represents the complete independence.

\section{Paper-and-pencil neglect assessments}

Two paper- and -pencil tasks were administrated to detect neglect: The Bells Test and the Line Bisection Test. Participants were instructed to avoid leaning to one side and to avoid adjusting the position of the paper during the assessment.

The Bells Test allows for qualitative and quantitative assessment of spatial neglect in the near extra-personal space. It requires circling 35 targets (bells) embedded within 280 distractors (horses, guitars, houses, etc.) on a $280 \mathrm{~mm}$ by $215 \mathrm{~mm}$ paper placed in the center of patient's field of view. The spatial distribution of the target figures was arranged so that 5 bells were located in 7 equally sized columns. The total number of circled bells was recorded and a difference of 5 bells omitted between the right and the left side indicated neglect. ${ }^{24}$

The Line Bisection Test is a subtest of the Behavioural Inattention Test (BIT):25 the participant is presented with three horizontal lines $(204 \mathrm{~mm})$ offset in a staircase fashion. The extent of each line is pointed out to the participant who was then instructed to estimate the middle of each line. Deviations from the midpoint drawn by the participant to the actual midpoint for each line were measured and scores ranging between 0 and 3 for each line were derived using the BIT template. A score less than 7 indicates a high probability of neglect. A pathological score in one of the two tests was considered sufficient for the diagnosis of neglect.

\section{Global cognitive functioning}

Mini-Mental State Examination (MMSE) globally assess cognitive functioning. It evaluates 5 areas: orientation, short-term memory, attention, delayed recall and language. ${ }^{22}$ It consists of 30 questions: 1 point for each correct answer, and 0 point for each wrong answer or no idea. The total score of the scale is $0-30$ point (cut-off $=24$ ). MMSE requires only 5-10 minutes to administer and is therefore practical to use serially and routinely.

\section{Statistical analysis}

A statistical analysis of the correlation of the Tinetti Index versus the Neglect presence was conducted. In this analysis the explanatory variable (feature) is the Tinetti
Index, while the response variable is the Neglect presence, classified with binary values ( $0=$ not present, $1=$ present $)$. A preliminary Anderson-Darling Normality Test confirmed, with a $\mathrm{P}$ value $<0.005$, the normality of the two groups distributions. A two-sample standard deviation test proved that the variances of the two groups differ at the 0.05 level of significance. A two-sample Student's $t$-test confirmed an analogous result for the means. The analyzes were carried out with the Minitab Statistical Software.

\section{Results}

In total, one hundred and sixty patients were evaluated for eligibility (Figure 1) and 89 were included in the study according to the inclusion criteria previously mentioned.

Demographic and clinical characteristics are summarized in Table I. Of the 89 patients, 55 were males and 34 females. We detected the presence of neglect in 22 patients (24.7\%) with the cognitive tests previously described, respectively in 12 males (54.5\%) and 10 females (45.4\%). Neglect was observed in 21 patients $(95.5 \%)$ with lesion localized in the right hemisphere. Consequently 21 patients were diagnosed with left neglect and only one patient with right neglect. There was no significant difference as regards age between neglect and non-neglect

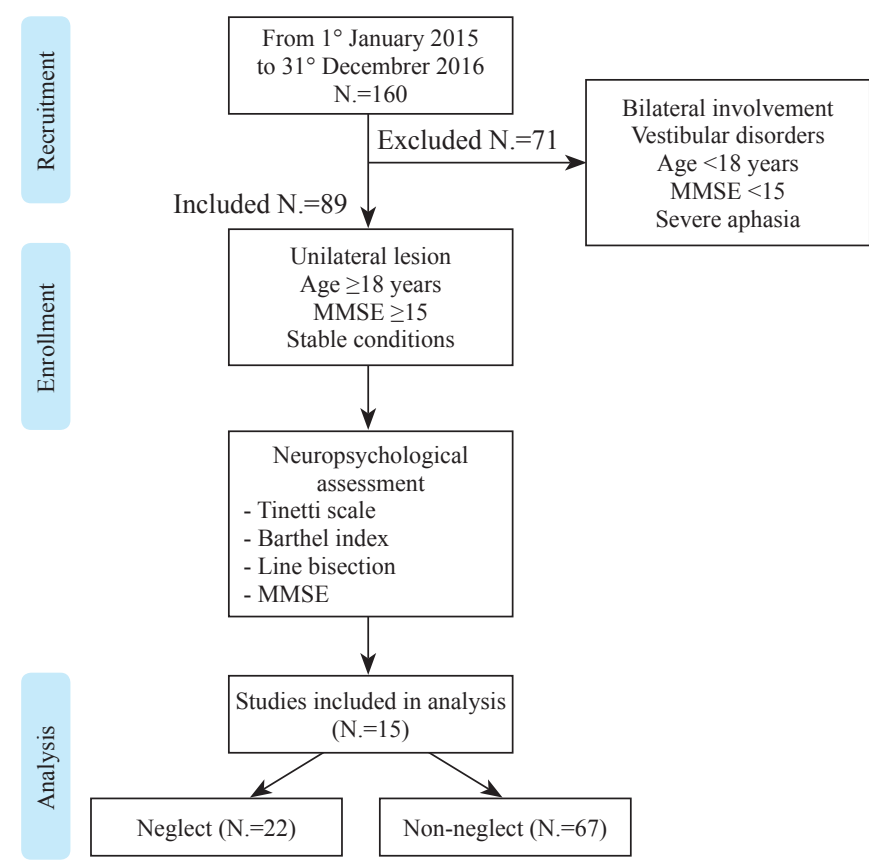

Figure 1.-Schematic overview of the protocol and the phases of recruitment, enrolment and analysis. 


\section{COPYRIGHT $^{\circledR} 2019$ EDIZIONI MINERVA MEDICA}

SPATIAL NEGLECT IN POST-STROKE PATIENTS

COLOMBO

TABLE I.-Demographic and clinical characteristics of enrolled patients.

\begin{tabular}{lcc}
\hline & $\begin{array}{c}\text { Neglect, N. }=22 \\
(24.7 \%)\end{array}$ & $\begin{array}{c}\text { Non-neglect, } \\
\text { N. }=67(75.3 \%)\end{array}$ \\
\hline $\begin{array}{l}\text { Age (years) Mean } \pm \text { SD } \\
\text { Gender }\end{array}$ & $72.13 \pm 8.45^{*}$ & $70.46 \pm 9.98^{*}$ \\
Male & $12(54.5 \%)$ & $43(64.1 \%)$ \\
Female & $10(45.4 \%)$ & $24(35.8 \%)$ \\
$\begin{array}{l}\text { Days post-stroke } \\
\text { Stroke type }\end{array}$ & $47^{*}$ & $39^{*}$ \\
$\quad$ Ischemic & $14(63.6 \%)$ & $40(59.7 \%)$ \\
$\quad$ Hemorrhagic & $8(36.3 \%)$ & $27(40.3 \%)$ \\
$\quad$ Lesion side & & \\
$\quad$ Left & $1(4.5 \%)$ & $42(62.7 \%)$ \\
Right & $21(95.5 \%)$ & $25(37.3 \%)$ \\
\hline
\end{tabular}

*There were no significant differences between neglect and no neglect patients in terms of age $(\mathrm{P}=0.22)$ and in terms of days post-stroke $(\mathrm{P}=0.09)$. SD: standard deviation.

TABLE II.-Outcome measures between neglect and non-neglect patients. Results for each tests are represented with mean and SD (standard deviation).

\begin{tabular}{|c|c|c|c|}
\hline & $\begin{array}{c}\text { Neglect N. }=22 \\
(\text { mean } \pm \text { SD })\end{array}$ & $\begin{array}{l}\text { Non-neglect } \mathrm{N} .=67 \\
(\text { mean } \pm \mathrm{SD})\end{array}$ & \\
\hline Tinetti Index & $2.36 \pm 3.7$ & $7.82 \pm 6.9$ & $\mathrm{P}<0.001$ \\
\hline Barthel Index & $21.27 \pm 14.1$ & $42.89 \pm 26.3$ & $\mathrm{P}<0.001$ \\
\hline \multicolumn{4}{|l|}{ Bells Test $(0-35)$} \\
\hline $\begin{array}{l}\text { Omissions (left minus } \\
\text { right or right minus left) }\end{array}$ & $6.59 \pm 0.9$ & $0.85 \pm 0.8$ & $\mathrm{P}<0.001$ \\
\hline Line bisection & $3.68 \pm 0.8$ & $8.2 \pm 0.7$ & $\mathrm{P}<0.001$ \\
\hline MMSE & $22.31 \pm 2.9$ & $23 \pm 3.6$ & $\mathrm{P}=0.18$ \\
\hline
\end{tabular}

Statistical significance between neglect and non-neglect patients was found in all tests for neglect assessment. Cognitive scores instead were comparable between the two groups $(\mathrm{P}>0.05)$

patients $(\mathrm{P}=0.22)$. The time between stroke and execution of scales was also comparable $(\mathrm{P}=0.09)$ with an average of 47 days post-stroke in the Neglect group and 39 days in Non-neglect patients.

All scales used to detect neglect showed significant differences between the two groups as shown in Table II. In details, BI resulted significantly lower $(\mathrm{P}<0.001)$ in patients with neglect (21.27 vs. 42.89 in no neglect ones). Furthermore, omissions recorder at the Bells Test were significantly higher $(\mathrm{P}<0.001)$ between neglect patients (mean $=6.59)$ and non-neglect patients (mean $=0.85$ ). In addition, neglect patients showed also lower scores $(\mathrm{P}<0.001)$ in the Line Bisection Test, with mean score of 3.68 in affected patients and 8.2 in no affected ones.

Considering MMSE Score, we found no significant difference ( $\mathrm{P}=0.18)$ so the two groups resulted to be comparable in terms of cognitive scores.

In Figure 2 the density plots using histograms for the two groups are shown. A two-sample $t$-test with the null

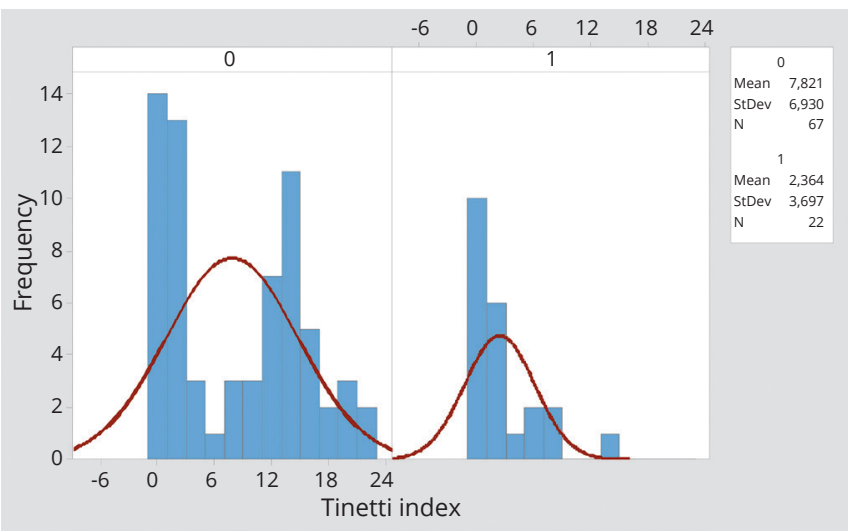

Figure 2.-Density plots with Normal curves of the two groups data ( 0 $=$ no neglect and $1=$ neglect stroke patients).

hypothesis of $\mu_{1}-\mu_{2}$ (difference of the two means) was applied. The null hypothesis was rejected with a $\mathrm{P}$ value $<0.001$.

In Figure 3, we represented Tinetti Index results between Neglect and Non neglect patients, which were found to be significantly different $(\mathrm{P}<0.001)$ (mean $=2.36$ in neglect patient and 7.82 in non-neglect ones).

Further confirmation of the relationship between Tinetti Index and Neglect was obtained with the calculation of the Spearman correlation coefficient, which turned out to be -0.347 , with $\mathrm{P}$ value $<0.001$. The negative sign of the coefficient is consistent with the behavior of the Tinetti Index, which decreases with the presence of the Neglect; the 0.347 value confirms the potential relationship between the feature and the response variable.

\section{Discussion}

The main aim of this study was to examine the possible predictive capacity of the Tinetti Test for the early diagnosis of neglect in post-stroke patients. Literature about use of Tinetti Test for detection of neglect is still lacking.

Previous studies 16,17 have proved that ecological scales can be very sensitive and reliable in the diagnosis of neglect by measuring behaviors and activities in daily life settings. The mobility assessment course ${ }^{16}$ was developed in order to measure the presence of neglect and its severity in a dynamic acts. It is important to underline that neglect is a heterogeneous syndrome, which manifests in many different ways; ${ }^{26}$ for this reason, it is unlikely that it can be captured exclusively with one task.

The dynamic and ecological characteristics of the Tinetti Test allow investigators to study neglect presence in a 


\section{COPYRIGHT $^{\odot} 2019$ EDIZIONI MINERVA MEDICA}

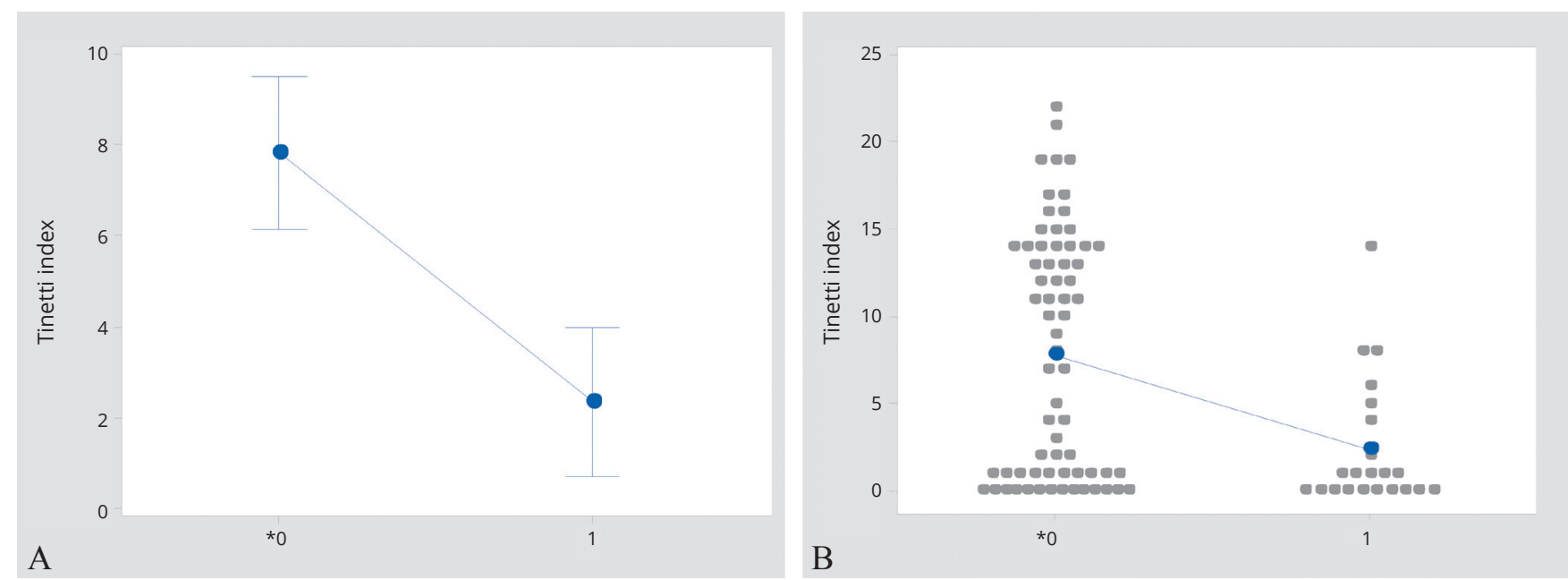

Figure 3.- Interval plot of Tinetti Index Individual standard deviations are used to calculate the intervals. A) Mean and Standard deviations represented for $* 0=$ no neglect and $1=$ neglect stroke patients; B) Detailed patient's scores for Tinetti Index and representation of population distribution.

quantitative way and to orient the rehabilitative treatment. As shown for other multitasking scales, the Tinetti Test should be sufficiently sensitive and specific in recognizing the presence of neglect in post-stroke patients. ${ }^{27-29}$ In a complex society people think, perform activities and move at high speed; therefore post-stroke patients require improvements in their functional capacities during activity of daily living. Neglect interferes with daily life activities and it has been associated with poorer functional and motor recovery, leaving patients with neglect less independent than stroke patients without neglect. ${ }^{12}$ In fact fundamental goals in clinical rehabilitation are the recovery of independent movements and good spatial orientation, since these skills are necessary for daily activities participation.

These considerations strengthen the view that clinical diagnosis of neglect requires preferably tests of different dynamics and complexity. It has been recognized that patients with neglect have severe difficulties in maintaining arousal during tasks This has been proved in different studies, where it has been found that neuropsychological assessment is often difficult to perform especially when there are no time limits, when stimuli are static, and when the attentional load is low. ${ }^{30}$ Nevertheless, a quick assessment of neglect would be beneficial since it would allow to perform other neurological tests reducing the risk of exhaustion in patients. Thus, the Tinetti should be early performed and added to the battery of tests specifically designed to detect neglect.

The data analysis of our 89 inpatients showed the presence of neglect in 22 patients $(24.7 \%)$. Functional assessments evaluated with Tinetti Test at the beginning of treat- ment showed significantly lower scores in patients with neglect $(2,3 / 28$ pints) than those without neglect $(7,8 / 28$ points) $(\mathrm{P}<0.001)$. Also the $\mathrm{BI}$ Score was significantly lower in patients with neglect $(\mathrm{P}<0.001)$ and this confirms that these patients showed a complex situation even in daily life activities and in balance and gait.

Our data pinpoint an inverse relationship between the decrease in the Tinetti Score and the increase probability to intercept patients with neglect. Therefore we can assume that the use of an easy and quick evaluation tool as the Tinetti Test as part of a complex evaluation could allow an earlier detection of neglect. It will be necessary to perform further studies in order to evaluate the sensitivity and specificity of the Tinetti Test in neglect diagnosis.

\section{Limitations of the study}

The main limitations of this study were the lack of data on visual perception, and the fact that the observation of patients by the evaluator was limited to physical activities, and does not fully explain the complexity of interaction between neglect and motor deficits. We underline the lack of information on clinical signs as a "limit" of our study. Due to the retrospective nature of the study we decided not to collect this information because examinations were conducted by several operators so they were not comparable.

\section{Conclusions}

Our study shows the importance of the Tinetti Test as an early indicator of neglect in post-stroke patients. This leads to the perspectives to validate this ecologically method in 


\section{COPYRIGHT $^{(\odot)} 2019$ EDIZIONI MINERVA MEDICA}

order to improve the assessment and management of patients with neglect.

We can thus conclude that this study marks the beginning for new opportunities for studying cognitive performances with ecological scales.

\section{References}

1. Price-Haywood EG, Harden-Barrios J, Carr C, Reddy L, Bazzano LA, van Driel ML. Patient-reported outcomes in stroke clinical trials 20022016: a systematic review. Qual Life Res 2019;28:1119-28.

2. Hochstenbach J, Donders R, Mulder T, Van Limbeek J, Schoonderwaldt H. Long-term outcome after stroke: a disability-orientated approach. Int J Rehabil Res 1996;19:189-200.

3. Czernuszenko A, Członkowska A. Risk factors for falls in stroke patients during inpatient rehabilitation. Clin Rehabil 2009;23:176-88.

4. Chen P, Chen CC, Hreha K, Goedert KM, Barrett AM. Kessler Foundation Neglect Assessment Process uniquely measures spatial neglect during activities of daily living. Arch Phys Med Rehabil 2015;96:869-876.e1.

5. Chen P, Hreha K, Kong Y, Barrett AM. Impact of spatial neglect on stroke rehabilitation: evidence from the setting of an inpatient rehabilitation facility. Arch Phys Med Rehabil 2015;96:1458-66.

6. Tinetti ME. Performance-oriented assessment of mobility problems in elderly patients. J Am Geriatr Soc 1986;34:119-26.

7. Heilman KM, Valenstein E, Watson RT. Neglect and related disorders. Semin Neurol 2000;20:463-70.

8. Gillen R, Tennen H, McKee T. Unilateral spatial neglect: relation to rehabilitation outcomes in patients with right hemisphere stroke. Arch Phys Med Rehabil 2005;86:763-7.

9. Stein MS, Kilbride C, Reynolds FA. What are the functional outcomes of right hemisphere stroke patients with or without hemi-inattention complications? A critical narrative review and suggestions for further research. Disabil Rehabil 2016;38:315-28.

10. Pérennou DA, Amblard B, Laassel M, Benaim C, Hérisson C, Pélissier J. Understanding the pusher behavior of some stroke patients with spatial deficits: a pilot study. Arch Phys Med Rehabil 2002;83:570-5.

11. Geurts AC, de Haart M, van Nes IJ, Duysens J. A review of standing balance recovery from stroke. Gait Posture 2005;22:267-81.

12. Nijboer T, van de Port I, Schepers V, Post M, Visser-Meily A. Predicting functional outcome after stroke: the influence of neglect on basic activities in daily living. Front Hum Neurosci 2013;7:182.

13. Jehkonen M, Laihosalo M, Kettunen JE. Impact of neglect on functional outcome after stroke: a review of methodological issues and recent research findings. Restor Neurol Neurosci 2006;24:209-15.
14. de Haart M, Geurts AC, Dault MC, Nienhuis B, Duysens J. Restoration of weight-shifting capacity in patients with postacute stroke: a rehabilitation cohort study. Arch Phys Med Rehabil 2005;86:755-62.

15. Carvalho ZMdF. Coelho JMA, Campos RR, Oliveira DCd, Machado WG, Maniva SJCdF. Use of the Tinetti Index to Assess Fall Risk in Patients with Sequelae of Stroke. Int J Phys Med Rehabil 2014;2:243.

16. Ten Brink AF, Visser-Meily JM, Nijboer TC. Dynamic assessment of visual neglect: The Mobility Assessment Course as a diagnostic tool. J Clin Exp Neuropsychol 2018;40:161-72.

17. Grech M, Stuart T, Williams L, Chen C, Loetscher T. The Mobility Assessment Course for the Diagnosis of Spatial Neglect: Taking a Step Forward? Front Neurol 2017;8:563.

18. Aravind G, Lamontagne A. Dual tasking negatively impacts obstacle avoidance abilities in post-stroke individuals with visuospatial neglect: task complexity matters! Restor Neurol Neurosci 2017;35:423-36.

19. Bowen A, Hazelton C, Pollock A, Lincoln NB. Cognitive rehabilitation for spatial neglect following stroke. Cochrane Database Syst Rev 2013;(7):CD003586

20. Rengachary J, d'Avossa G, Sapir A, Shulman GL, Corbetta M. Is the posner reaction time test more accurate than clinical tests in detecting left neglect in acute and chronic stroke? Arch Phys Med Rehabil 2009;90:2081-8.

21. Collin C, Wade DT, Davies S, Horne V. The Barthel ADL Index: a reliability study. Int Disabil Stud 1988;10:61-3.

22. Folstein MF, Folstein SE, McHugh PR. "Mini-mental state". A practical method for grading the cognitive state of patients for the clinician. $\mathrm{J}$ Psychiatr Res 1975;12:189-98.

23. Shah S, Vanclay F, Cooper B. Improving the sensitivity of the Barthel Index for stroke rehabilitation. J Clin Epidemiol 1989;42:703-9.

24. Gauthier L, Dehaut F, Joanette Y. The Bells test: A quantitative and qualitative test for visual neglect. Int J Clin Neuropsychol 1989;11:49-54.

25. Halligan PW, Cockburn J, Wilson BA. The behavioural assessment of visual neglect. Neuropsychol Rehabil 1991;1:5-32.

26. Stone SP, Halligan PW, Marshall JC, Greenwood RJ. Unilateral neglect: a common but heterogeneous syndrome. Neurology 1998;50:1902-5.

27. Blini E, Romeo Z, Spironelli C, Pitteri M, Meneghello F, Bonato M, et al. Multi-tasking uncovers right spatial neglect and extinction in chronic left-hemisphere stroke patients. Neuropsychologia 2016;92:147-57.

28. Bonato $M$, Priftis $K$, Marenzi R, Umiltà C, Zorzi M. Increased attentional demands impair contralesional space awareness following stroke. Neuropsychologia 2010;48:3934-40.

29. Bonato M. Unveiling residual, spontaneous recovery from subtle hemispatial neglect three years after stroke. Front Hum Neurosci 2015;9:413

30. Azouvi P. The ecological assessment of unilateral neglect. Ann Phys Rehabil Med 2017;60:186-90.

Conflicts of interest.-The authors certify that there is no conflict of interest with any financial organization regarding the material discussed in the manuscript. Authors' contributions.-Paola Colombo, Giovanni Taveggia and Liala De Armas contributed in the conception and design of the study; Paola Colombo and Monica Tiboni acquired and analyzed the data; Paola Colombo, Giovanni Taveggia, Liala De Armas, Deborah Chiesa and Rachele Penati contributed in drafting and editing the manuscript, figures and tables; Roberto Casale provided a final revision of the abstract. All authors approved the final draft.

Article first published online: July 5, 2019. - Manuscript accepted: July 1, 2019. - Manuscript revised: May 16, 2019. - Manuscript received: July 19, 2018. 